\title{
EDUCAÇÃO AMBIENTAL COMO INSTRUMENTO DE SENSIBILIZAÇÃO COMUNITÁRIA: O CASO EM UMA ESCOLA PÚBLICA DO MUNICÍPIO DE PASSO FUNDO/RS
}

\author{
Denise Regina Toledo dos Santos ${ }^{1}$, Sandra Regina Toledo dos Santos ${ }^{2}$ \\ ${ }^{1}$ Autora, Graduada em Administração/UPF, Especialista em Gestão Ambiental/UPF, 2010, denise-re@bol.com.br . \\ ${ }_{2}^{2}$ Professora Orientadora - Adjunto I, Mestre em Controladoria, UPF, sandratche@yahoo.com.br.
}

\section{Resumo}

A Gestão Ambiental (GA) é uma prática que vem ganhando espaço nas instituições públicas e privadas. No setor público, especialmente na área educacional, a conscientização ambiental acaba proporcionando uma abrangência maior, repercutindo nas famílias através da absorção do conhecimento e na comunidade em geral. O objetivo principal deste estudo consiste em avaliar o entendimento dos alunos de 5a a 8a série e professores de uma escola pública municipal de Passo Fundo quanto à educação ambiental como instrumento no processo de sensibilização comunitária. A metodologia utilizada foi de cunho descritivo, aplicado em estudo de caso, de modo qualitativo e com análise quantitativa, sendo a amostra composta por 12 professores e 144 alunos de uma escola municipal nas séries indicadas, no turno da manhã, sendo utilizado como instrumento de coleta de dados um questionário específico para cada grupo com 10 questões fechadas, moldadas pela escala de Likert. Os resultados apontam a necessidade de uma melhor preparação dos professores para a abordagem do assunto junto aos alunos e, estes por sua vez, entendem que podem auxiliar efetivamente na construção de uma consciência coletiva quanto ao meio ambiente.

Palavras-chave: Educação ambiental. Gestão. Meio ambiente. Organizações.

\section{INTRODUÇÃO}

A abordagem da Gestão Ambiental (GA) é uma prática que vem ganhando espaço nas instituições públicas e privadas. Através dela é possível a mobilização das organizações para se adequar à promoção de um meio ambiente ecologicamente equilibrado, cujo objetivo é a busca pela melhoria constante dos produtos, serviços e ambiente de trabalho saudável, levando em consideração as políticas de proteção ao meio ambiente.

Atualmente, a gestão ambiental está relacionada à estratégia da organização, porque além de estimular a qualidade dos processos que refletem essa temática, também possibilita a redução de custos diretos (redução de desperdícios com água, energia e matérias-primas) e nos custos indiretos (indenizações por danos ambientais). Dessa forma, quando a empresa reconhece os principais aspectos e impactos que as suas atividades provocam no meio ambiente, tende a planejar melhor as ações de gerenciamento ambiental.

A Gestão Ambiental é no entendimento de Kraemer (2004) "o sistema que inclui à estrutura organizacional atividades de planejamento, responsabilidades, práticas, procedimentos, processos e recursos para desenvolver, implementar, atingir, analisar criticamente e manter a 


\title{
SANTOS \& SANTOS, vol.(5), n5, p. 1038 - 1046, 2012. Monografias Ambientais IsSN: 2236-1308
}

1039

política ambiental". Na busca pela eficiência da utilização dos recursos naturais é que as organizações elegem como estratégica a gestão ambiental.

No processo de gestão ambiental encontra-se uma concepção de educação que atua como elemento estruturante na organização do processo de ensino-aprendizagem, construído com os sujeitos nele envolvidos, para que ocorra controle social sobre as decisões, que via de regra, afetam o destino das atuais e futuras gerações (LAYRARGUES, 2002).

A educação ambiental é um instrumento importante nesse processo, pois está regulamentada pela Lei Federal 9.795/1999, a qual traz em seu capítulo I, Artigo $1^{\circ}$, o seguinte:

Entende-se por educação ambiental os processos por meio do qual o indivíduo e a coletividade constroem valores sociais, conhecimentos, habilidades, atitudes e competências voltadas para a conservação do meio ambiente, bem de uso comum do povo, essencial à sadia qualidade de vida e sua sustentabilidade.

Já no Artigo $3^{\circ}$ da mesma lei, trata-se desse tema como parte do processo educativo mais amplo, onde todos têm direito à educação ambiental através da incumbência participativa de vários segmentos da sociedade, tais como os constantes no Inciso $V$ que descreve:

Às empresas, entidades de classe, instituições públicas e privadas, cabe promover programas destinados à capacitação dos trabalhadores, visando à melhoria e ao controle efetivo sobre o ambiente de trabalho, bem como sobre as repercussões do processo produtivo no meio ambiente.

De acordo com Layrargues (2002, p. 169):

\begin{abstract}
um processo educativo eminentemente político, que visa ao desenvolvimento nos educandos de uma consciência crítica acerca das instituições, atores e fatores sociais geradores de riscos e respectivos conflitos sócioambientais. Busca uma estratégia pedagógica do enfrentamento de tais conflitos a partir de meios coletivos de exercício da cidadania, pautados na criação de demandas por políticas públicas participativas conforme requer a gestão ambiental democrática.
\end{abstract}

Diante disso, presume-se que a educação ambiental seja desenvolvida também pelos gestores públicos, como forma de estabelecer uma relação sensibilizadora de todos os cidadãos, de modo que esse processo iniciaria dentro do ambiente das escolas municipais para criar uma consciência ecológica e ambientalmente correta junto aos alunos, que poderão se constituir mais tarde em agentes multiplicadores.

As estratégias de enfrentamento da problemática ambiental, para surtirem o efeito desejável na construção de sociedades sustentáveis, estão relacionadas à articulação coordenada entre todos os tipos de intervenção ambiental direta, onde as ações em educação ambiental são premissa básica para um resultado satisfatório. Dessa forma, assim como as medidas políticas, jurídicas, institucionais e econômicas voltadas à proteção, recuperação e melhoria sócio ambiental, despontam também as atividades no âmbito educativo (PRONEA, 2005).

Nesse contexto, as empresas conforme o segmento em que atuam, são condicionadas a se adaptarem aos novos modelos de gestão, com responsabilidade social e ambiental. No setor público, especialmente na área educacional, o cenário não é diferente, visto que a sensibilização no ambiente escolar acaba proporcionando uma abrangência maior das questões ambientais, repercutindo nas famílias através da absorção do conhecimento, bem como na comunidade em geral. 


\section{SANTOS \& SANTOS, vol.(5), n5, p. 1038 - 1046, 2012.

Diante do exposto, este estudo questiona: Como se dá o entendimento dos alunos e professores de uma escola municipal de Passo Fundo/RS quanto à educação ambiental no processo de sensibilização comunitária?

O objetivo principal consiste em avaliar o entendimento dos alunos de $5 \underline{a}$ a $8^{a}$ série e dos professores de uma escola pública municipal de Passo Fundo quanto à educação ambiental como instrumento no processo de conscientização comunitária, desdobrando-se nos objetivos específicos para relacionar a educação ambiental no processo de responsabilidade ambiental e social do poder público, bem como estabelecer um nexo entre o entendimento identificado e a construção de uma conscientização comunitária quanto à gestão do meio-ambiente.

O presente estudo justifica-se pelo fato de que um programa de educação ambiental pode se constituir num instrumento catalisador de informações no processo de sensibilização da preservação dos recursos naturais e da compreensão das questões ambientais. Ainda, envolve um conjunto de atividades sistematizadas e com a participação dos diversos setores da sociedade. Tais atividades demonstram não só os benefícios do programa, mas também colaboram no sentido de dotar os gestores públicos de subsídios para decisões através dos resultados obtidos com esta pesquisa.

Este trabalho desdobra-se em quatro seções: a primeira inicia-se por esta introdução, na segunda seção consta a metodologia utilizada, na terceira está o resultado e discussão dos dados e, por fim, constam as conclusões seguida das referências bibliográficas.

\section{METODOLOGIA}

Esta pesquisa caracteriza-se como estudo de caso, por se constituir no estudo de um ou de poucos objetos, de maneira que permita seu amplo e detalhado conhecimento (DIEHL, TATIM, 2004).

Caracteriza-se também como pesquisa descritiva e qualitativa, sendo que o objetivo da pesquisa descritiva segundo Diehl e Tatim (2004) é a descrição das características de uma população ou fenômeno, sendo que a característica peculiar é a utilização de técnicas padronizadas de coleta de dados, como questionário e observação sistemática; bem como a qualitativa é onde o pesquisador tem certa liberdade para realizar seu estudo.

A população consiste em uma escola do município selecionado, para a efetiva implantação de um projeto de educação ambiental e que será extensivo às demais escolas. A amostra selecionada é composta por 12 professores da escola que lecionam para 144 alunos do Ensino Fundamental, no turno da manhã. A faixa etária dos alunos abrange dos 11 aos 15 anos de idade.

A escola encontra-se num bairro próximo ao centro da cidade, com uma infra-estrutura composta por farmácias, supermercados, ambulatório, creche, linhas de ônibus freqüentes em direção ao centro e outros bairros, posto policial, padaria, bem como os demais estabelecimentos para atender as necessidades emergentes da população que ali reside.

No entendimento de Marconi e Lakatos (2008) a etapa onde se inicia o processo de aplicação dos instrumentos elaborados e das técnicas selecionadas, com o intuito de se efetuar a coleta dos dados prevista, se dá através de pesquisas bibliográficas, questionários e formulários aplicados à amostra. Assim, foi utilizado um questionário específico para cada grupo com 10 questões fechadas que inicialmente, passou por um pré-teste a fim de validar o instrumento dirigido aos respondentes. A fase da aplicação do instrumento deu-se no mês de setembro/2010 e foi moldado pela escala de Likert ao considerar como critério para respostas, o seguinte: 
1: sem condições de responder

2: discordo plenamente

3: discordo em partes

4: concordo em partes

5: concordo plenamente

Os dados coletados foram apresentados de forma descritiva e a análise realizada de modo quantitativo e com a representação gráfica dos resultados.

Deve-se considerar como limitação, que este estudo poderá não refletir os mesmos resultados nas demais escolas municipais, devido a realidade do entorno da escola selecionada.

\section{RESULTADOS E DISCUSSÃO DOS DADOS}

A análise foi disposta em dois grupos, conforme os respondentes, para melhor entendimento dos resultados encontrados.

\subsection{Grupo de professores}

O grupo de professores é formado por graduados e pós-graduados, que atuam com alunos do Ensino Fundamental no turno da manhã da escola selecionada, sendo que através da aplicação do instrumento buscou-se relacionar como os respondentes inserem-se e tratam da questão educacional voltada ao meio ambiente no processo de sensibilização comunitária.

As respostas revelaram as constatações expostas na Tabela 1:

Tabela 1: Respostas obtidas sobre educação ambiental com os professores

\begin{tabular}{|c|c|c|c|c|c|}
\hline \multirow[t]{2}{*}{ Questões } & \multicolumn{5}{|c|}{ Respostas em \% } \\
\hline & 1 & 2 & 3 & 4 & 5 \\
\hline 1) Você conhece o tema educação ambiental & 12,5 & 37,5 & 12,5 & 25,0 & 12,5 \\
\hline 2) Você conhece o tema sustentabilidade ambiental & 25,0 & 25,0 & 12,5 & 25,0 & 12,5 \\
\hline $\begin{array}{l}\text { 3) O desenvolvimento do senso crítico dos alunos em relação aos } \\
\text { temas necessita de melhor preparo por parte dos professores } \\
\text { para o debate }\end{array}$ & - & - & 25,0 & 50,0 & 25,0 \\
\hline $\begin{array}{c}\text { 4) É necessário o debate dos temas para que possamos } \\
\text { desenvolver uma sensibilização comunitária }\end{array}$ & - & - & - & 25,0 & 75,0 \\
\hline $\begin{array}{l}\text { 5) A escola deve ser um canal de educação nesse processo } \\
\text { evolutivo da consciência ecológica }\end{array}$ & - & - & 12,5 & 25,0 & 62,5 \\
\hline $\begin{array}{l}\text { 6) A Prefeitura, enquanto órgão público, deve desenvolver } \\
\text { programas de conscientização ambiental }\end{array}$ & - & - & - & 37,5 & 62,5 \\
\hline $\begin{array}{l}\text { 7) As escolas devem preparar reuniões coletivas entre pais e } \\
\text { alunos para o despertar da consciência comunitária ecológica }\end{array}$ & 12,5 & - & 12,5 & 25,0 & 50,0 \\
\hline $\begin{array}{l}\text { 8) O uso correto da água e a coleta seletiva de lixo são } \\
\text { preocupações da escola nas atividades diárias }\end{array}$ & 12,5 & 25,0 & 25,0 & 25,00 & 12,5 \\
\hline $\begin{array}{l}\text { 9) Gincanas ecológicas auxiliam no início desse programa } \\
\text { educativo }\end{array}$ & - & 12,5 & 12,5 & 50,0 & 25,0 \\
\hline $\begin{array}{l}\text { 10) A sustentabilidade da sociedade quanto aos recursos naturais, } \\
\text { parte da educação ambiental recebida por grupos mais jovens }\end{array}$ & - & - & - & 25,0 & 75,0 \\
\hline
\end{tabular}

Fonte: Dados primários

Evidencia-se pelos resultados apresentados na Tabela 1 que o entendimento dos professores quanto ao tema educação e sustentabilidade ambiental ainda não é consenso, 
atingindo cerca de menos da metade do total que detém algum tipo de conhecimento sobre tal temática. Isso pode estar relacionado a pouca reflexão da importância dessa abordagem pelos professores como agentes envolvidos no processo educacional, voltado à conscientização das gerações futuras quanto às questões ambientais.

No entanto, percebe-se que estes entendem a necessidade de uma melhor preparação quanto ao tema para o desenvolvimento em sala de aula, bem como a utilização dessa metodologia como papel fundamental na conscientização comunitária, através dos alunos.

Observou-se que tanto a escola quanto o poder público municipal, devem instituir mecanismos que possibilitem gerar um debate coletivo no trato ambiental, através de algumas estratégias como palestras, seminários, distribuição de cartilhas e outras formas capazes de mobilizar os indivíduos para melhor qualidade coletiva de vida, a partir da conscientização do papel que cada um exerce na sociedade.

Não ficou evidente nas respostas, sobre a questão que aborda o uso correto da água e coleta seletiva de lixo, como uma premissa seguida pela escola. Caso haja a intenção em formar a sensibilização coletiva dos alunos, torna-se necessário que a escola estabeleça as regras em seu próprio âmbito para o uso adequado da água e implante módulos que tratem da coleta seletiva do lixo, seja por parte dos alunos ou por parte dos demais integrantes da comunidade escolar, a fim de consolidar essa dinâmica no próprio ambiente interno.

Os professores entendem que atividades diversificadas, como o caso das gincanas ecológicas sem a intenção de gerar competição entre grupos, pode contribuir para um melhor resultado no projeto de educação ambiental, aproximando assim os alunos da realidade ambiental no local onde vivem.

Foi evidenciada a quase unanimidade na opinião de que os grupos mais jovens podem consolidar melhor a importância da sustentabilidade ambiental. Assim, o direcionamento das atividades sensibilizadoras poderá surtir efeito positivo muito mais rápido se adotada a metodologia proposta, em séries onde os alunos tenham possibilidade de entendimento uniforme da temática, como o grupo definido nesse trabalho, ou seja, o Ensino Fundamental.

As escolas municipais desempenham um papel importante no processo de conscientização, pelo fato de estarem localizadas muito próximas ao seu público, de modo que têm capacidade em contribuir efetivamente num projeto que possibilite a conscientização comunitária a cerca de qualquer tema.

A Figura 1 demonstra a relação obtida pela escala de Likert entre as questões levantadas na Tabela 1: 


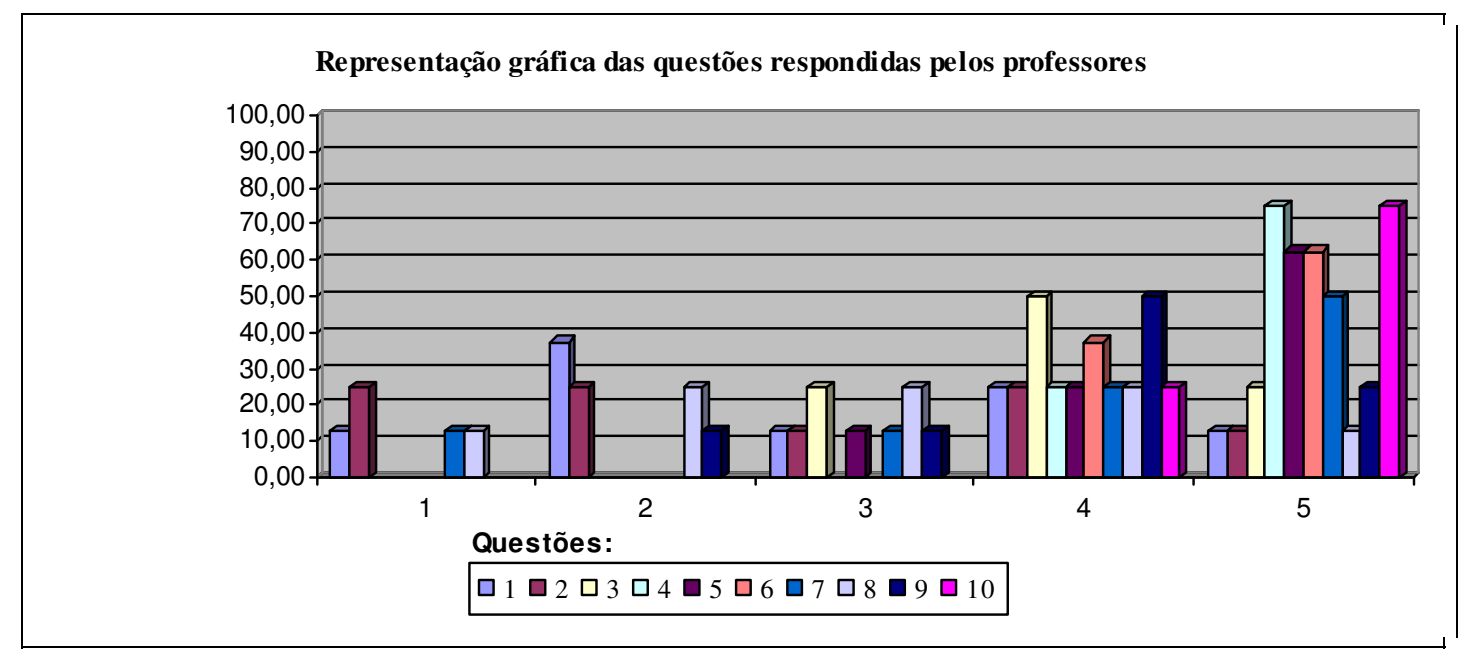

Figura 1: Representação gráfica das respostas dos professores na pesquisa Fonte: Dados primários

Observa-se na Figura 1 que a grande freqüência de respostas deu-se nos valores da escala 4 e 5, ou seja, respectivamente entre o "concordo em partes" e o "concordo plenamente". Os maiores e melhores percentuais obtidos deram-se nas questões 4 e 10 deste questionário, com $75 \%$ das respostas obtidas na escala 5 em "concordo plenamente".

\subsection{Grupo de alunos}

O grupo de alunos no questionário aplicado evidenciou o exposto na Tabela 2:

Tabela 2: Respostas obtidas sobre educação ambiental com os alunos

\begin{tabular}{|c|c|c|c|c|c|}
\hline \multirow[t]{2}{*}{ Questões } & \multicolumn{5}{|c|}{ Respostas em \% } \\
\hline & 1 & 2 & 3 & 4 & 5 \\
\hline 1) Você conhece o tema educação ambiental & 18,75 & 25,00 & 12,5 & 18,75 & 25,00 \\
\hline 2) Você conhece o tema sustentabilidade ambiental & 25,00 & 25,00 & 25,00 & 12,5 & 12,5 \\
\hline $\begin{array}{l}\text { 3) Você sabe como é estabelecida a coleta seletiva de lixo e como } \\
\text { sua finalidade é proposta }\end{array}$ & 25,00 & 25,00 & 37,5 & 12,5 & - \\
\hline $\begin{array}{l}\text { 4) O uso correto da água deve ser considerada nas ações diárias } \\
\text { desenvolvidas em sua casa e na escola }\end{array}$ & - & - & 12,5 & 37,5 & 50,00 \\
\hline $\begin{array}{l}\text { 5) Você deseja auxiliar na sensibilização comunitária sobre a } \\
\text { questão ambiental }\end{array}$ & - & - & 12,5 & 25,00 & 62,5 \\
\hline $\begin{array}{l}\text { 6) Você considera que o tema ambiental deve ser melhor } \\
\text { explorado na sua escola }\end{array}$ & 12,5 & - & - & 37,5 & 50,00 \\
\hline $\begin{array}{l}\text { 7) As práticas ensinadas na escola sobre meio ambiente poderão } \\
\text { ser repassadas aos seus familiares sem qualquer restrição }\end{array}$ & - & - & - & 37,5 & 62,5 \\
\hline $\begin{array}{l}\text { 8) Você participaria das atividades propostas por sua escola para } \\
\text { o despertar da consciência comunitária ecológica }\end{array}$ & - & - & - & - & 100,00 \\
\hline $\begin{array}{l}\text { 9) Você entende que a educação ambiental pode ser um } \\
\text { instrumento de conscientização comunitária quanto ao meio } \\
\text { ambiente }\end{array}$ & 10,00 & - & - & 37,5 & 52,5 \\
\hline $\begin{array}{l}\text { 10) Em sua casa, assuntos ambientais são discutidos como forma } \\
\text { de entendimento coletivo }\end{array}$ & - & 10,00 & 12,5 & 37,5 & 40,00 \\
\hline
\end{tabular}

Fonte: Dados primários 
Percebe-se pela análise da Tabela 2 que o conhecimento dos alunos quanto ao tema educação e sustentabilidade ambiental ainda é mínimo entre os respondentes, menos da metade do total detém algum tipo de instrução sobre tal temática, ou seja, $25 \%$ do total. Isso pode estar relacionado a pouca reflexão da importância desta abordagem na escola pesquisada. Apesar de responderem que há um diálogo em casa com o restante da família sobre a questão ambiental, entende-se que isso não ocorre de modo constante.

A funcionalidade da coleta seletiva de lixo também foi constatada como não esclarecida suficientemente. Os alunos não visualizam a importância do tema para o trato dos resíduos residenciais e a finalidade para a qual foi criada a coleta seletiva.

No entanto, a grande maioria dos alunos entendeu que a escola deve iniciar o processo de sensibilização do uso correto da água e estariam dispostos a desempenhar um papel comunitário ao divulgar as informações ambientais, bem como a atuação da escola torna-se fundamental para essa nova visão participativa.

A aceitação pelos alunos foi total quanto ao início de atividades voltadas a formação da sensibilização ambiental, para que posteriormente possam se tornar multiplicadores dessas informações junto às suas famílias e o meio onde vivem. Foi identificado que somente $10 \%$ dos respondentes disseram não ter condições de responder sobre a efetiva implantação de um programa dessa natureza para a conscientização comunitária.

A Figura 2 apresenta a relação obtida pela escala de Likert para as questões levantadas no questionário aplicado aos alunos:

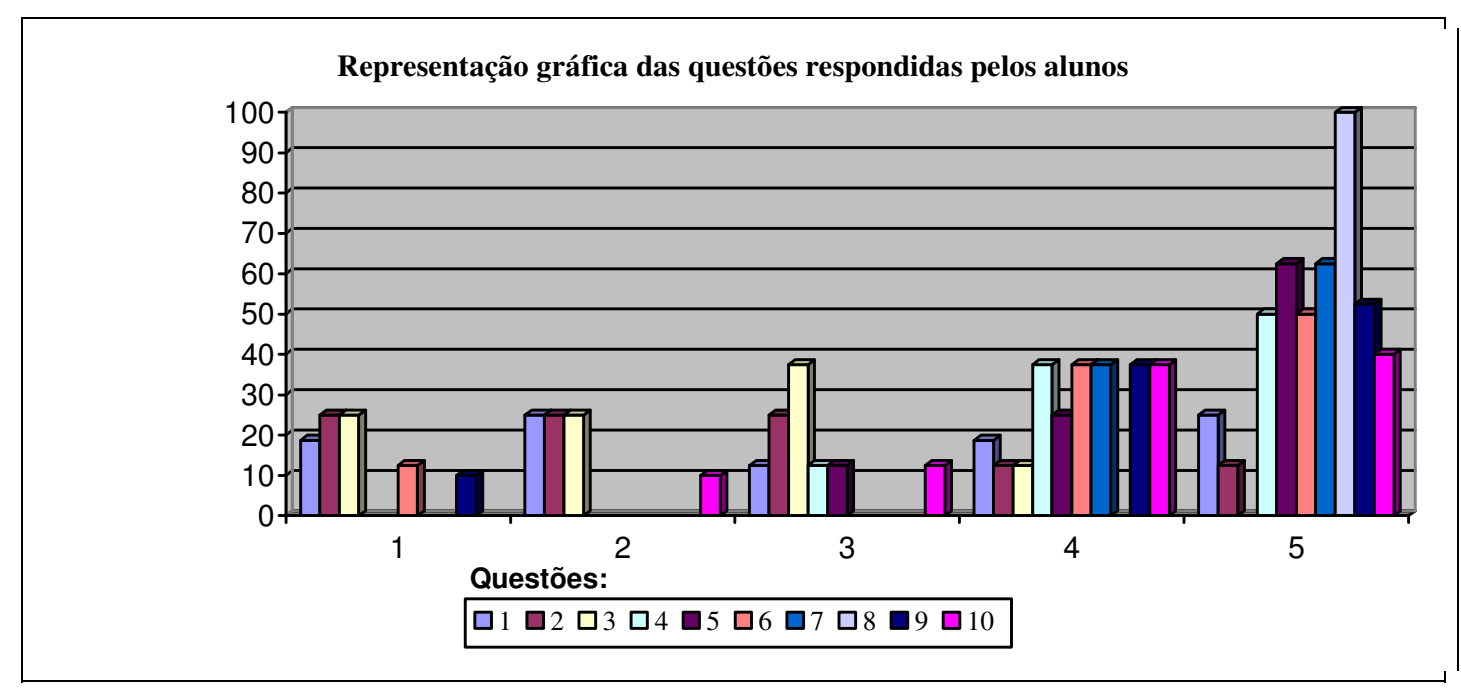

Figura 2: Representação gráfica das respostas dos alunos na pesquisa

Fonte: Dados primários

Observa-se na Figura 2 que a grande freqüência de respostas deu-se na escala 4 e 5, as quais evidenciam as melhores respostas do questionário. Os maiores e melhores percentuais obtidos deram-se nas questões 5, 7 e 8 da Tabela 2. Na média destes percentuais, observa-se acima dos $60 \%$ de concordância efetiva nas respostas obtidas.

Percebe-se que tanto professores quanto alunos convergem para a importância do tema, destacando o devido preparo dos professores para a abordagem do tema em sala de aula e os anseios dos alunos quanto à inserção no debate junto a comunidade onde vivem, refletindo assim 
as ações que o poder público municipal pode desenvolver enquanto agente propagador dos benefícios da sustentabilidade ambiental.

\section{CONCLUSÕES}

A sociedade, ao buscar a sustentabilidade de suas atividades pode obter resultados positivos quando utilizar mecanismos como a educação ambiental junto às gerações mais novas, para tornar esse um processo de abrangência comunitária.

Para tanto, este estudo buscou avaliar como se dá o entendimento dos alunos e professores de uma escola municipal quanto à educação ambiental no processo de sensibilização comunitária.

A proposta metodológica abrangeu um estudo de caso, descritivo, qualitativo e de análise quantitativa, onde foi aplicado como instrumento de pesquisa durante o mês de setembro/2010 um questionário composto por 10 questões fechadas, junto aos grupos formados por 12 professores e 144 alunos vinculados ao Ensino Fundamental, do turno da manhã de uma escola do município selecionado.

As evidências apontam para um nível ainda moderado de contextualização do tema, bem como a necessidade de melhor qualificação e preparo dos professores quanto a metodologia voltada à educação ambiental.

Em virtude da realidade local, torna-se evidente que a escola poderá desenvolver mais ações relacionadas a sensibilização dos seus alunos, principalmente, por questões básicas como a coleta seletiva de lixo e o uso adequado da água. Nesse sentido, espera-se que a medida que ocorra maior nível de envolvimento interno da escola com essas questões, seja possível aproximar a comunidade desse objetivo comum pela busca da sustentabilidade ambiental.

O governo municipal ao promover essa dinâmica reflexiva com os alunos do ensino fundamental, estará oportunizando o conhecimento sobre como as empresas, o próprio governo e os cidadãos, enquanto consumidores estabelecem suas relações coletivas quando o assunto é ecologia e sustentabilidade ambiental.

Conclui-se pela pesquisa, que na prática, em virtude da vasta legislação e métodos necessários ao sucesso da educação e gestão ambiental, o sistema de ensino municipal ainda apresenta dificuldades no alinhamento das estratégias educacionais quanto ao tema, quando se trata de difundir a busca pelo equilíbrio sustentável e ambiental através de políticas públicas melhor definidas e voltadas para ao despertar do senso comum. 


\section{REFERÊNCIAS:}

BARBIERI, José Carlos. Gestão Ambiental empresarial: conceitos, modelos e instrumentos. São Paulo: Saraiva, 2004.

BRASIL, Lei 9795/99, institui a Política Nacional de Educação Ambiental, 1999.

DIEHL, Astor Antônio; TATIM, Denise Carvalho. Pesquisa em ciências sociais aplicadas: Métodos e técnicas. São Paulo: Person Prentice Hall, 2004.

KRAEMER, Maria Elisabeth; TINOCO, João Prudêncio. Contabilidade e gestão ambiental. 1. Ed., São Paulo: Atlas, 2004.

LAYRARGUES, P.P. A crise ambiental e suas implicações na educação. In: Quintas, J.S (Org) Pensando e praticando educação ambiental na gestão do meio ambiente. 2a ed. Brasília: IBAMA, 2002.

MARCONI, Marina de Andrade; LAKATOS, Eva Maria. Fundamentos de metodologia científica. 6. ed. 6. reimpr. São Paulo: Atlas, 2008.

PRONEA, Programa nacional de educação ambiental. Ministério do Meio Ambiente. 3a Ed., Brasília: Ministério do Meio Ambiente, 2005. 